\title{
Identificación molecular de Entamoeba histolytica, Entamoeba dispar y Entamoeba moshkovskii en niños con diarrea en Maracaibo, Venezuela
}

Zulbey Rivero ${ }^{1,2}$, Lisbeth Villarreal ${ }^{3}$, Ángela Bracho ${ }^{2}$, Carem Prieto ${ }^{4,5}$, Rafael Villalobos ${ }^{1}$

${ }^{1}$ Laboratorio de Parasitología, Universidad del Zulia, Maracaibo, Venezuela

${ }^{2}$ Laboratorio de Parasitología, Universidad Técnica de Manabí, Portoviejo, Ecuador

${ }^{3}$ Laboratorio Clínico del Servicio Autónomo, Hospital Universitario de Maracaibo, Maracaibo, Venezuela

${ }^{4}$ Departamento de Investigación, Universidad Católica de Cuenca, Cuenca, Ecuador

${ }^{5}$ Centro de Investigaciones Endocrino-Metabólicas “Dr. Félix Gómez", Universidad del Zulia, Maracaibo, Venezuela

Introducción. Las amebas no patógenas Entamoeba dispar, Entamoeba moshkovskii y Entamoeba bangladeshi son morfológicamente idénticas a Entamoeba histolytica, parásito responsable de la amebiasis, por lo cual se necesitan técnicas moleculares para diferenciarlas.

Objetivo. Determinar la frecuencia de las diferentes especies de Entamoeba mediante reacción en cadena de la polimerasa (Polymerase Chain Reaction, PCR) en muestras fecales de niños menores de cinco años con diarrea, provenientes de Maracaibo (Venezuela).

Materiales y métodos. Se recolectó una muestra fecal por individuo en 75 niños con diarrea (grupo de casos) y en 25 niños sin diarrea (grupo control). Las heces se evaluaron mediante examen microscópico, método de concentración de formól-éter y PCR múltiple anidada en una sola ronda para identificar E. histolytica, E. dispar y E. moshkovskii. Además, se hizo una encuesta en la que se recopilaron los datos demográficos, signos, manifestaciones clínicas y estrato socioeconómico de los niños.

Resultados. El $48 \%$ de los participantes (38 del grupo de casos y 10 del grupo de control) tenían enteroparásitos. Solo en las muestras de cuatro de los niños, se encontraron quistes del complejo Entamoeba (tres en el grupo de casos y uno en el de control). Mediante PCR se amplificaron nueve muestras ( $9 \%$ ) para la detección de las amebas estudiadas. En el grupo de casos se registraron tres $(28,13 \%)$ de E. histolytica, cuatro $(30,50 \%)$ de E. dispar y una $(9,37 \%)$ de $E$. moshkovskii, en tanto que solo una (25\%) muestra amplificó para $E$. dispar en el grupo de control.

Conclusión. En general, predominó E. dispar; sin embargo, todos los infectados con $E$. histolytica se detectaron en el grupo de niños con diarrea y se detectó el primer caso de $E$. moshkovskii en la región.

Palabras clave: Entamoeba; Entamoeba histolytica; reacción en cadena de la polimerasa multiplex; niño; diarrea; Venezuela.

Molecular identification of Entamoeba histolytica, E. dispar, and E. moshkovskii in children with diarrhea from Maracaibo, Venezuela

Introduction: Entamoeba histolytica is an amebiasis-producing parasite. However, Entamoeba dispar, Entamoeba moshkovskii, and Entamoeba bangladeshi are nonpathogenic amoebae morphologically identical to it and, therefore, molecular techniques are required for their differentiation.

Objective: To determine the frequency of Entamoeba species by polymerase chain reaction $(\mathrm{PCR})$ in fecal samples from children under five years with diarrhea from Maracaibo (Venezuela).

Materials and methods: A fecal sample per individual was collected from 75 children with diarrhea (case group) and 25 children without diarrhea (control group). Stools were evaluated by microscopic examination, formol-ether concentration method, and nestedmultiplex PCR in a single round for the identification of E. histolytica, E. dispar, and $E$. moshkovskii. In addition, a survey was conducted in which demographic data, signs, clinical manifestations, and socioeconomic status were registered.

Results: In total, $48 \%$ of the children (38 from the case group and 10 from the control group) had intestinal parasites. Only four children presented cysts of the Entamoeba complex in their samples (three from the case group and one from the control group). By means of PCR, nine samples (9\%) amplified for the studied amoebae. In the case group, three $(28.13 \%)$ amplified for E. histolytica, four (30.50\%) for E. dispar, and one $(9.37 \%)$ for $E$. moshkovskii while only one (25\%) sample amplified for E. dispar in the control group. 
Conclusion: In general, E. dispar predominated. Nevertheless, all those infected with $E$. histolytica were detected within the group of children with diarrhea and we reported the first case of E. moshkovskii in the region.

Keywords: Entamoeba; Entamoeba histolytica; multiplex polymerase chain reaction; child; diarrea; Venezuela.

Entamoeba histolytica es un parásito protozoario causante de la amebiasis en humanos. Esta infección afecta principalmente a personas que viven en deficientes condiciones de higiene en los países en desarrollo, donde es endémica; los niños menores de cinco años son los más propensos a desarrollarla. La Organización Mundial de la Salud (OMS) estima que, aproximadamente, 500 millones de personas están infectadas con el parásito y el $10 \%$ de ellas presenta amebiasis invasiva. Esta parasitosis es considerada un importante problema de salud pública, pues llega a producir cuadros de disentería amebiana que, de no ser tratados, pueden llevar al paciente a la deshidratación y hasta la muerte (1-3).

Ngobeni, et al., señalan que el término ameba engloba las especies pertenecientes a los géneros Entamoeba, Endolimax e lodamoeba; entre ellas, se destaca Entamoeba histolytica, única ameba intestinal que se reconoce como patógena, pues es la causante de la amebiasis. Las restantes especies que pueden encontrarse en la luz del intestino incluyen Entamoeba dispar, E. moshkovskii, E. bangladeshi, E. hartmannii, E. coli, E. polecki, Endolimax nana e lodamoeba butschlii, consideradas no patógenas (4).

Existen otras especies de Entamoeba, como E. gingivalis, que se encuentra principalmente en la cavidad oral humana, y que también se ha encontrado en Egipto en el aparato genitourinario de usuarias de dispositivos anticonceptivos intrauterinos (5), y E. nuttalli, que prevalece en primates no humanos, aunque fue detectada en un cuidador de un zoológico en Bélgica (6).

Las amebas del género Entamoeba comparten muchas características morfológicas y biológicas, pero se caracterizan, en particular, por poseer cromatina adosada a la membrana nuclear interna y presentar dos formas evolutivas durante su ciclo de vida: los trofozoítos o formas vegetativas y los quistes o formas de resistencia (7). Los trofozoítos y quistes de $E$. histolytica, E. dispar, E. moshkovskii y E. bangladeshi son morfológicamente indistinguibles entre sí y, por consenso, se las ha agrupado en el llamado complejo Entamoeba $(2,8)$.

El diagnóstico de la amebiasis comúnmente se hace mediante el examen coprológico y la detección al microscopio de quistes o trofozoítos que morfológicamente corresponden a E. histolytica o, menos frecuentemente, mediante biopsia de tejido mucoso. Sin embargo, el reconocimiento de $E$. dispar y la detección de E. moshkovskii en seres humanos, además del registro de una nueva especie, E. bangladeshi, ha complicado el diagnóstico, pues todas son morfológicamente idénticas, aunque diferentes desde el punto de vista genético y bioquímico $(9,10)$.

El examen microscópico de materia fecal presenta serias limitaciones, especialmente, la incapacidad de distinguir entre E. histolytica, E. dispar, E. moshkovskii y E. bangladesí, y el hecho de que solo puede confirmarse la presencia de E. histolytica cuando las muestras presentan trofozoítos hematófagos, situación que es bastante infrecuente (9). En este sentido, los métodos moleculares como la PCR han demostrado una mayor sensibilidad de detección comparados con otras técnicas de diagnóstico de la amebiasis, 
por lo que se ha convertido en la prueba de referencia para el diagnóstico de la amebiasis intestinal (3).

No se encontraron publicaciones previas sobre la prevalencia de $E$. moshkovskii en Venezuela y existe muy poca información en cuanto a la prevalencia de E. histolytica y E. dispar en el país. En ese contexto, el objetivo del presente estudio fue determinar mediante métodos moleculares la frecuencia de estas amebas en niños del municipio Maracaibo, estado Zulia (Venezuela), y determinar la asociación de dicha frecuencia con la presencia o ausencia de diarrea.

\section{Materiales y métodos}

\section{Diseño del estudio, población y muestra}

Se diseñó un estudio de tipo descriptivo, prospectivo y transversal. La población incluyó a todos los niños menores de cinco años con diarrea (área de urgencias) y sin diarrea (triaje de pediatría) atendidos en el Servicio Autónomo Hospital Universitario de Maracaibo, entre enero y julio de 2014.

Se recolectaron 100 muestras de heces frescas de la siguiente manera: 75 de niños menores de cinco años con diarrea aguda, considerados como el grupo de casos, y 25 muestras de heces de niños menores de cinco años sin diarrea, considerados como el grupo de control. Los criterios de inclusión en el grupo de casos fueron: niños menores de cinco años, de cualquier sexo, con diarrea, atendidos en el área de urgencias del Hospital y que no hubieran recibido tratamiento antiparasitario en los dos meses anteriores. Los niños evaluados fueron estratificados por grupos etarios según la clasificación de Quintero (11).

Se hizo una encuesta respondida por representantes de todos los niños incluidos en el estudio, para recabar los datos demográficos de edad, sexo y procedencia, y los signos y síntomas de diarrea, presencia de deshidratación, vómito y fiebre. Posteriormente, se hizo la estratificación socioeconómica según Graffar y modificada por Méndez, et al. (12).

\section{Análisis parasitológico}

Se recolectó una muestra fecal por niño. Para ello, a cada representante se le entregó un envase recolector plástico nuevo, limpio, de boca ancha y tapa de rosca (sin preservativos), y se le dieron en forma oral y escrita las recomendaciones necesarias para la correcta recolección de la muestra fecal.

Las muestras fueron trasladadas al Laboratorio de Parasitología de la Escuela de Bioanálisis de la Universidad del Zulia, donde se hizo el examen macroscópico y el microscópico de la muestra fecal, así como la prueba con el método de concentración de formól-éter (13). Los resultados del examen coproparasitológico fueron entregados a los representantes de los niños. Una porción de la muestra fue congelada a $-20{ }^{\circ} \mathrm{C}$ para efectuar posteriormente el análisis molecular (PCR) en el Laboratorio de Biología Molecular del Centro de Investigaciones Endocrino-Metabólicas "Dr. Félix Gómez", con el fin de detectar E. histolytica, E. dispar y E. moshkovskii.

\section{Análisis molecular}

La extracción y purificación del ADN genómico de Entamoeba spp. se llevó a cabo en el Laboratorio de Parasitología de la Escuela de Bioanálisis 
de la Universidad del Zulia, utilizando un procedimiento estandarizado que incorporó algunos pasos de protocolos de lisis enzimática y choque térmico, y mecánicos, descritos previamente por Rivero, et al. (14).

Todas las reacciones de PCR se llevaron a cabo en un volumen total de 40,0 $\mu \mathrm{l}$ con $8 \mu \mathrm{l}$ de solución tampón para PCR 10X, 2,4 $\mu \mathrm{l}$ de cloruro de magnesio $\left(\mathrm{MgCl}_{2}\right)$ 25,0 mmol/L; $1 \mu \mathrm{l}$ de la mezcla de desoxirribonucleótidos ( $5,0 \mathrm{mmol} / \mathrm{L}$ de cada uno); $0,5 \mu \mathrm{l}$ de GoTaq ${ }^{\mathrm{TM}}$ polimerasa de Promega (5 UI/ $\mu \mathrm{l}) ; 4 \mu \mathrm{l}$ de la mezcla de oligonucleótidos (50 pmol de cada iniciador) y $15,0 \mu \mathrm{l}$ del ADN de muestra.

Como controles de referencia, se emplearon la cepa HM-1:IMSS de $E$. histolytica, la cepa SAW760 de E. dispar, y la cepa Laredo de E. moshkovskii, todas gentilmente donadas por Graham Clark del London School of Hygiene and Tropical Medicine. En estos casos, se utilizaron $6 \mu \mathrm{l}$ de ADN para los pruebas de amplificación por PCR de los controles y, además, se utilizó un control negativo de reacción que solo contenía $1 \mu \mathrm{l}$ de agua.

Como blanco genómico, se utilizó la secuencia de genes similares al ARNr 16S, con un fragmento específico para el género Entamoeba y los fragmentos específicos (iniciadores) para las especies E. histolytica, E. dispar y $E$. moshkovskii (Eurofins Genomics) descritos por Khairnar, et al. (15) (cuadro 1). La identidad de las secuencias de oligonucleótidos utilizados y el peso molecular de los fragmentos esperados fueron confirmados en la BLAST (http://www.ncbi.nlm.nih.gov/blast/).

Se siguió un protocolo de PCR múltiple anidada, estandarizado por los autores del presente estudio para ser efectuado en una sola reacción a partir del protocolo original de Ngui, et al. (16), en el que se hizo el anidado de la región específica para el género Entamoeba de genes similares al ARNr $16 \mathrm{~S}$. Este incluyó una desnaturalización inicial a $94{ }^{\circ} \mathrm{C}$ durante 10 minutos, seguida de 15 ciclos con los siguientes pasos: desnaturalización a $94{ }^{\circ} \mathrm{C}$ durante un minuto, apareamiento a $56{ }^{\circ} \mathrm{C}$ durante un minuto y extensión a $72{ }^{\circ} \mathrm{C}$ durante 1:15 minutos (no se obtuvo el producto para ser verificado en gel de agarosa). En la misma amplificación, se programaron 25 ciclos del siguiente esquema: a $94{ }^{\circ} \mathrm{C}$ durante un minuto, a $48{ }^{\circ} \mathrm{C}$ durante un minuto, a $72{ }^{\circ} \mathrm{C}$ durante $1: 15$ minutos y, por último, a $72{ }^{\circ} \mathrm{C}$ durante 10 minutos. En este paso, se empleó la PCR múltiple para la caracterización genética de E. histolytica, E. dispar y E. moshkovskii, y se obtuvieron fragmentos de 439 pb, 174 bp y 553 bp. Los tubos Eppendorf se mantuvieron a $4{ }^{\circ} \mathrm{C}$ hasta salir del equipo. Todas las muestras fueron corridas en un termociclador Eppendorf (PTC-100 Peltier Thermal Cycler ${ }^{\mathrm{TM}}$ ).

Cuadro 1. Oligonucleótidos iniciadores utilizados para las especies Entamoeba histolytica, Entamoeba dispar y Entamoeba moshkovskii

\begin{tabular}{|c|c|c|c|}
\hline Parásito & $\begin{array}{c}\text { Nombre del } \\
\text { iniciador }\end{array}$ & $\begin{array}{c}\text { Secuencia del iniciador } \\
\left(5^{\prime} \text { a } 3^{\prime}\right)\end{array}$ & $\begin{array}{l}\text { Tamaño del } \\
\text { producto }(\mathrm{pb})\end{array}$ \\
\hline \multirow[t]{2}{*}{ Entamoeba spp. } & $E-1$ & TAAGATGCAGAGCGAAA & $\approx 800$ \\
\hline & $E-2$ & GTACAAAGGGCAGGGACGTA & \\
\hline \multirow[t]{2}{*}{ E. moshkovskii } & Mos-1 & GAAACCAAGAGTTTCACAAC & 553 \\
\hline & Mos-2 & CAATATAAGGCTTGGATGAT & \\
\hline \multirow[t]{2}{*}{ E. histolytica } & $\mathrm{EH}-1$ & AAGCATTGTTTCTAGATCTGAG & 439 \\
\hline & $\mathrm{EH}-2$ & AAGAGGTCTAACCGAAATTAG & \\
\hline \multirow[t]{2}{*}{ E. dispar } & ED-1 & TCTAATTTCGATTAGAACTCT & 174 \\
\hline & ED-2 & TCCСTACСTATTAGACATAGC & \\
\hline
\end{tabular}


Los productos amplificados se separaron por electroforesis en gel de agarosa al 2,0 \% en cámaras horizontales (Bio-Rad Laboratories). Como solución tampón de corrida, se utilizó solución amortiguadora de $89 \mathrm{mM}$ de tris-borato y $2 \mathrm{mM}$ de EDTA, pH: 8 (TBE), la corrida se llevó a cabo a $100 \mathrm{v} /$ $\mathrm{cm}$ durante 30 minutos. Los geles se tiñeron con bromuro de etidio (10 mg/ $\mathrm{ml}$ ), luego, se visualizaron en un transiluminador ultravioleta (Uvitec) y se fotografiaron con el sistema de fotodocumentación DigiDoc UVPTM. Se incluyó un marcador de peso molecular de 100 pb DNA Ladder de Promega.

\section{Análisis estadístico}

La frecuencia de las amebas en relación con las variables estudiadas se expresó con la distribución de frecuencias absolutas y con porcentajes. Para el análisis de los resultados obtenidos, se utilizó el programa estadístico SPSS $^{\top M}$, versión 17 (SPSS Inc., Chicago, III, USA). Se empleó la prueba estadística de ji al cuadrado, el test exacto de Fisher o la correlación de Spearman, según correspondiese, para las pruebas de significación estadística entre las variables en estudio. El valor de $p<0,05$ se aceptó como estadísticamente significativo (17).

\section{Consideraciones éticas}

El estudio fue revisado y aprobado por el Comité de Ética del Hospital. Por tratarse de una investigación no terapéutica en la que se emplearon muestras fecales de niños menores, los padres autorizaron la entrega de la muestra mediante un consentimiento informado y dieron la información necesaria para la encuesta. Se guardó en absoluta confidencialidad la información de los pacientes.

\section{Resultados}

La mediana de edad de los niños estudiados fue de $3 \pm 1,093$ años, siendo el menor de cinco meses y el mayor de cinco años. En total, participaron 38 niñas (31 en el grupo de casos y siete en el grupo de control) y 62 varones (42 en el grupo de casos y 18 en el grupo de control). El $48 \%$ de los niños (38 del grupo de casos y 10 del grupo de control) presentaron enteroparásitos según el examen microscópico directo o por concentración. Mediante este procedimiento, se detectaron quistes del complejo Entamoeba en las muestras fecales de tres $(4,6 \%)$ individuos del grupo de casos y de uno $(7,1 \%)$ del grupo de control.

Como resultado de la PCR aplicada a las 100 muestras, se amplificaron nueve muestras biológicas (figura 1), distribuidas de la siguiente manera: tres muestras con E. histolytica, cinco con E. dispar y una con E. moshkovskii.

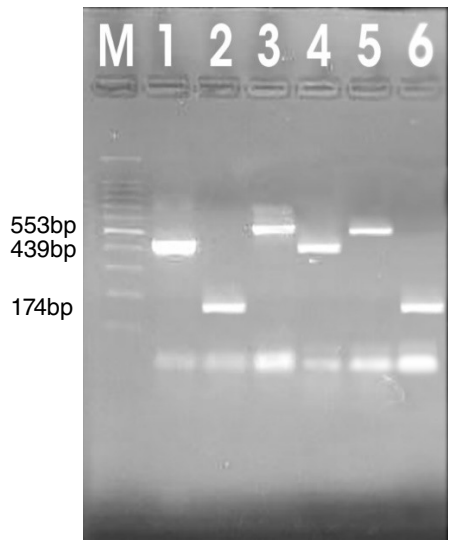

M: marcador de peso molecular. 1: control de referencia de Entamoeba histolytica (HM-1: IMSS). 2: control de referencia de Entamoeba dispar (SAW 760). 3: control de referencia de Entamoeba moshkovskii (cepa Laredo). 4, 5 y 6: ADN extraído de muestras de heces de pacientes positivos para cada una de las amebas estudiadas

Figura 1. Identificación por PCR de Entamoeba histolytica, Entamoeba dispar y Entamoeba moshkovskii 
Cuadro 2. Resultados de la PCR por especie de Entamoeba en el grupo de casos y en el de control

\begin{tabular}{lcc}
\hline \multirow{2}{*}{ Especies parasitarias } & \multicolumn{2}{c}{ Grupo estudiado } \\
\cline { 2 - 3 } & Casos & $\begin{array}{c}\text { Control } \\
\mathbf{n}\end{array}$ \\
\hline Entamoeba histolytica & 3 & 0 \\
Entamoeba dispar & 4 & 1 \\
Entamoeba moshkovskii & 1 & 0 \\
\hline Total & 8 & 1 \\
\hline
\end{tabular}

En el cuadro 2 se presentan los resultados de la PCR según los grupos de casos y controles. Se encontraron ocho muestras positivas en el grupo de casos, tres correspondían a E. histolytica, cuatro a E. dispar y una a E. moshkovskii, en tanto que, en el grupo de control, solo se detectó un individuo con E. dispar; no hubo casos de infección simultánea por dos o más especies de las amebas estudiadas entre los niños evaluados.

Los parásitos que se encontraron simultáneamente con E. histolytica fueron los helmintos Ascaris lumbricoides y Trichuris trichiura, pero no se la encontró asociada con ningún protozoario intestinal. En los niños con E. dispar, se presentó la mayor cantidad de asociaciones. Se observó en conjunto con Blastocystis sp. (16,6\%), con protozoarios como E. coli $(33,3$ $\%)$, E. nana (16,6 \%) y Giardia lamblia (16,6\%), y con helmintos como $A$. lumbricoides (16,6\%). En el caso de E. moshkovskii, esta no se observó asociada a ningún otro parásito. Se detectaron infecciones exclusivas por E. histolytica y E. dispar, un caso de cada una, sin asociación con ningún helminto o protozoario intestinal.

Mediante el examen microscópico solo se observaron cuatro muestras positivas para el complejo Entamoeba, todas pertenecientes al grupo de preescolares. Una vez efectuado el procesamiento por PCR, se detectó un mayor número de casos, con nueve niños positivos y presencia de estas amebas tanto en el grupo de lactantes mayores como en el de lactantes menores, además de algunos casos más entre los mismos preescolares. En general, se encontró un predominio de las amebas en el grupo de niños entre dos y cinco años, con $3 \%$ para E. histolytica y $4 \%$ para E. dispar. Apenas un caso de E. dispar se detectó en lactantes mayores. Cabe destacar que el único caso de E. moshkovskii correspondía a un lactante menor (seis meses). No se encontró una diferencia significativa en esta variable $(p>0,05)$.

En cuanto a la prevalencia de las amebas por sexo, se apreció que la mayoría de los casos de infección por E histolytica, E. dispar y E. moshkovskii se detectó en el sexo masculino, aunque no se determinó una diferencia significativa $(p>0,05)$.

En cuanto a las variables de prevalencia de las amebas y el estrato socioeconómico de los niños, se evidenció que todos los casos de infección por E. histolytica correspondían a niños en situación de pobreza crítica, en tanto que los casos de E. dispar se encontraron repartidos entre los dos estratos más pobres de la escala (pobreza relativa y crítica), y el único caso de E. moshkovskii detectado pertenecía el estrato de pobreza relativa.

\section{Discusión}

La mayoría de los estudios epidemiológicos sobre la infección por $E$. histolytica se desarrollaron antes de la descripción de las especies del complejo Entamoeba. Por ello, existe una clara necesidad de desarrollar 
estudios epidemiológicos para distinguir entre las especies de amebas y determinar la verdadera prevalencia de la infección por E. histolytica. En el presente estudio, se lograron identificar mediante PCR E. histolytica, E. dispar y E. moshkovskii en las heces de niños menores de cinco años con y sin diarrea, atendidos en el Servicio Autónomo Hospital Universitario de Maracaibo.

En las muestras analizadas, predominó la especie E. dispar (cinco muestras), seguida de E. histolytica (tres muestras). Estos resultados coinciden con el estudio previo de Bracho, et al. (18), en niños con diarrea atendidos en el Hospital, en el que predominaron las infecciones por $E$. dispar. Estos autores refieren que, en seis muestras, identificaron ADN de $E$. dispar y, en dos, ADN de E. histolytica, y en ninguna hubo asociación entre las amebas estudiadas.

En un estudio en comunidades rurales al noreste de Suráfrica, se registraron prevalencias de $4,1 \%$ de E. histolytica, de $14,7 \%$ de E. dispar y de $15,9 \%$ de E. moshkovskii (19). Sharbathkori, et al. (20), determinaron la prevalencia de Entamoeba spp. en niños con disentería de Irán y encontraron E. histolytica y E. dispar en dos (2/25) y tres (3/25) muestras, respectivamente. Asimismo, en Colombia, López, et al. (21), hicieron estudios para diferenciar el complejo E. histolytica-E. dispar mediante la detección de Gal-GalNAclectina y PCR. Sus resultados arrojaron una prevalencia de 0,6 a $1,4 \%$ para E. histolytica y de 15 a $17 \%$ para E. dispar. En múltiples estudios basados en pruebas de biología molecular a nivel internacional, se señala el predominio de las infecciones por E. dispar frente a las de E. histolytica $(8,22-25)$.

Algunos estudios en la población general a nivel nacional e internacional contrastan con estos resultados. Es el caso de Mora, et al. (26), quienes establecieron la prevalencia de E. histolytica y E. dispar en pacientes con diarrea de Cumaná (Venezuela), mediante PCR, y reportaron una prevalencia de E. histolytica de $6,3 \%$ y de E. dispar de $4,44 \%$, detectando cuatro casos de infecciones mixtas. Los más afectados por ambas especies fueron niños y jóvenes. Ngui, et al. (16), estudiaron comunidades rurales de Malasia y refieren que la infección con $E$. histolytica $(75,0 \% ; 39 / 52)$ fue la más común, seguida de E. dispar (30,8 \%; 18/52) y E. moshkovskii (5,8 \%; 3/52). De estos casos, $33(63,5 \%)$ individuos presentaban solo E. histolytica, 10 (19,2\%) portaban exclusivamente E. dispar y tres (5,8 \%) solo E. moshkovskii; seis muestras (11,5 $\%)$ presentaron infección mixta de E. histolytica y E. dispar. Asimismo, Roshdy, et al. (27), mediante PCR múltiple anidada y PCR en tiempo real de pacientes con disentería en un hospital del Cairo, Egipto, encontraron 10,3\% de prevalencia de E. histolytica y $8,7 \%$ de E. dispar, y no detectaron casos de E. moshkovskii.

En el presente estudio, solo se detectó un caso de E. moshkovskii en un niño de seis meses de edad con diarrea. Es importante resaltar que este es el primer informe de E. moshkovskii en niños de la región zuliana y en el país. El primer reporte de esta ameba en humanos fue recogido por Haque, et al. (28), en una niña de Bangladesh. Estudios posteriores en ese mismo país revelaron una prevalencia de E. moshkovskii del $21 \%$ en niños de dos a cinco años mediante herramientas moleculares (29).

En Latinoamérica hay muy pocas referencias sobre la detección de $E$. moshkovskii en humanos; solo en Ecuador, Colombia, Brasil y Venezuela se han hecho investigaciones sobre esta especie. Levecke (30) refiere que, de 674 muestras de una comunidad rural al sur de Ecuador, solo 101 contenían quistes del complejo Entamoeba; sin embargo, mediante PCR-RLHB se detectaron $22,8 \%$ casos de E. dispar, en tanto que no se 
encontraron infecciones por E. histolytica ni E. moshkovskii. Bachkanji (31) evaluó mediante PCR 150 muestras de niños de 0 a 10 años del estado Sucre (Venezuela), que al microscopio resultaron positivas para el complejo Entamoeba, en tanto que utilizando herramientas moleculares el 19,30\% de ellas amplificó para E. histolytica, el $4 \%$ para E. dispar y el 4,70 \% presentó asociación de ambas amebas, pero no se detectó E. moshkovskii.

En el estudio de López, et al. (32), en un área rural del centro de Colombia, se encontró mediante PCR múltiple una frecuencia del 49,1\% (89/181); al diferenciar por especie, el 23,2 \% (42/181) de las muestras fue positivo para E. dispar, el 25,4 \% (46/181), para E. moshkovskii y, el 0,55 \% (1/181), para E. histolytica; además, se observaron infecciones mixtas de $E$. dispar y $E$. moshkovskii en 4,42 \% (8/181) de las muestras. Asimismo, Soares, et al. (33), estudiaron pacientes que asistían a un sistema de salud pública en Bahía (Brasil), mediante técnicas moleculares e inmunológicas. Por microscopía, se encontró una prevalencia de 0,49\% del complejo Entamoeba en 273 de 55.218 pacientes. De estos 273 individuos con microscopía positiva, solo 90 aceptaron participar en el estudio, entre los cuales, el 8,9\% (8/90) fueron positivos para $E$. histolytica por serología. En las muestras analizadas por PCR, el 80 \% (72/90) fueron positivas para E. dispar, aunque no fue posible identificar E. histolytica ni E. moshkovskii y, en el resto de las muestras (18/90), no hubo amplificación. Puede concluirse entonces que, de los países mencionados, solo en Colombia se había reportado la presencia de E. moshkovskii.

Es importante mencionar el estudio realizado por Ngui, et al. (34), en el cual se examinaron 504 muestras fecales de humanos y perros mediante microscopía y PCR en Malasia, se encontró que la especie más común era E. dispar (26,5\%; 13/49), seguida por E. histolytica y E. moshkovskii (con $20,4 \%$ para cada especie). En los animales, E. moshkovskii (46,7\%) fue la especie más común, seguida por E. histolytica y E. dispar, con $20,0 \%$ y 13,3 $\%$, respectivamente. Todo ello demuestra la presencia de la especie patógena de Entamoeba en perros, los que podrían ser un reservorio o un huésped mecánico para la amebiasis humana.

Al evaluar la presencia de las amebas en los dos grupos estudiados, se encontró que E. histolytica solo se detectó en el grupo de niños con diarrea y no en el grupo control. E. dispar, considerada como una especie no patógena, sí se encontró en ambos grupos de estudio, aunque en porcentajes diferentes. El único caso de E. moshkovskii también fue detectado en el grupo de niños con diarrea.

A pesar de que el número de individuos estudiados en el grupo control fue menor, es importante señalar que E. histolytica solo se detectó en el grupo de casos. Si bien la literatura científica refiere la posibilidad de individuos asintomáticos con E. histolytica (portadores asintomáticos) (35-37), en el presente estudio no se detectó esta situación, pues todos los pacientes infectados presentaban diarrea. Es innegable la capacidad patogénica de E. histolytica, como se ha demostrado en múltiples publicaciones (38-41), y en este caso, la coincidencia del hallazgo del parásito y la diarrea confirman esta premisa. Samie, et al. (19), refieren que solo E. histolytica estuvo asociada estadísticamente con diarrea en su estudio sobre la distribución de Entamoeba en comunidades rurales de Suráfrica. La diarrea en los niños infectados por E. dispar y E. moshkovskii podría explicarse por la asociación con otros enteroparásitos que la producen (por ejemplo, G. lamblia), situación observada en el presente estudio. 
Los estudios de Ugboko, et al. (42), indican que las enfermedades diarreicas parasitarias de importancia para la salud pública son la amebiasis (Entamoeba histolytica), la criptosporidiosis (Cryptosporidium spp.) y la giardiasis (G. lamblia), lo que puede comprobarse por el predominio de las amebas encontradas en este estudio en el grupo de niños con diarrea, a pesar de que no todas las amebas identificadas se consideran patógenas.

Mediante el examen microscópico, solo se observaron cuatro muestras positivas para el complejo Entamoeba, todas en el grupo de preescolares. Una vez efectuado el procesamiento por PCR, se logró evidenciar un mayor número de casos, resultando positivos nueve niños, con casos tanto en el grupo de lactantes mayores como en el de lactantes menores, además de algunos más dentro del grupo de los preescolares, lo que era predecible, pues la detección del ADN parasitario mediante PCR es mucho más sensible que la microscopía $(3,8,27,33)$.

En cuanto a la presencia de las amebas según la edad, en general, se encontró un predominio en el grupo de los preescolares, con $3 \%$ para $E$. histolytica y $4 \%$ para E. dispar. Sin embargo, no se evidenció una diferencia estadísticamente significativa entre las variables.

Los resultados del presente estudio difieren de los de Rivero, et al. (14), en individuos de una comunidad del estado Zulia, en el que se detectaron casos de estas amebas en los menores de dos años, lo que pudiera explicarse por los cuidados maternos que reciben estos niños, así como por el efecto protector contra E. histolytica que confieren el calostro y la leche materna en los lactantes $(43,44)$.

Se observó una total congruencia entre los resultados microscópicos del complejo Entamoeba y los de la PCR. Los cuatro casos detectados mediante microscopía también fueron positivos por PCR, y fueron dos de $E$. histolytica y dos de E. dispar. Por supuesto, dado que la PCR es un método más sensible y específico, con ella se detectaron cinco casos más que no habían sido diagnosticados mediante el examen microscópico. Esto difiere de lo informado por Bracho, et al. (18), quienes no observaron coincidencia entre los resultados del examen directo de heces y los resultados por PCR en niños del Servicio Autónomo Hospital Universitario de Maracaibo. En este estudio, mediante el examen microscópico no se detectaron muestras con E. histolytica y E. dispar, en tanto que mediante PCR, ocho muestras amplificaron para alguna de las especies de amebas. Los autores consideraron factible que las formas evolutivas de dichas amebas se encontraran en muy poca cantidad o parcialmente destruidas, por lo que no pudieron ser detectadas mediante microscopía y sí mediante PCR, que es una técnica mucho más sensible.

Aunque las especies estudiadas se encontraron en los niños pertenecientes a los estratos de pobreza relativa y pobreza crítica, el mayor porcentaje (seis casos) se encontró entre aquellos en situación de pobreza crítica. Esto permite relacionar la presencia de estas amebas, especialmente la patógena $E$. histolytica, con las peores condiciones de vivienda de todos los estratos, los ingresos más bajos y el menor grado de instrucción de los padres de familia. Se hace hincapié en las condiciones de la vivienda, principalmente, ya que son las más relacionadas con las condiciones sanitarias. Según la escala de Graffar, en el estrato V, el tipo de vivienda corresponde a un rancho con condiciones sanitarias marcadamente inadecuadas. Estos resultados coinciden con los de otros estudios a nivel 
nacional e internacional $(25,34,45-47)$ en los que se ha encontrado que los parásitos intestinales están asociados principalmente a las malas condiciones higiénicas, el escaso saneamiento del entorno y la precariedad socioeconómica de las familias.

En conclusión, predominó la especie E. dispar entre los niños estudiados; sin embargo, los casos de E. histolytica se detectaron solo en el grupo de niños con diarrea y en situación de pobreza crítica. Además, se encontró la primera evidencia de infección por E. moshkovskii en humanos en Venezuela, lo que requiere la continuación de estudios similares en otras comunidades.

\section{Agradecimientos}

A Nancy Guillén, del Instituto Pasteur en París, Francia, institución que donó todos los iniciadores utilizados. A Clark del London School of Hygiene and Tropical Medicine, por la donación de las cepas de referencia para el control.

\section{Referencias}

1. Ríos-Uil J, Mercadillo-Pérez P, Yuil de Ríos E, Ríos-Castro M. Amebiasis cutánea. Conceptos actuales. Rev Med Hosp Gen Mex. 2012;75:114-22.

2. Cui Z, Li J, Chen Y, Zhang L. Molecular epidemiology, evolution, and phylogeny of Entamoeba spp. Infec Genet Evol. 2019;75:104018 https://doi.org/10.1016/j.meegid.2019.104018

3. Carrero J, Reyes-López M, Serrano-Luna J, Shibayama M, Unzueta J, León-Sicairos N, et al. Intestinal amoebiasis: 160 years of its first detection and still remains as a health problem in developing countries. Int J Med Microbiol. 2020;310:151358. https://doi.org/10.1016/j.ijmm.2019.151358

4. Ngobeni R, Samie A, Moonah S, Watanabe K, Petri WA, Gilchrist C. Entamoeba species in South Africa: Correlations with the host microbiome, parasite burdens, and first description of Entamoeba bangladeshi outside of Asia. J Infect Dis. 2017;216:1592-600. https://doi.org/10.1093/infdis/jix535

5. Foda AA, El-Malky MM. Prevalence of genital tract infection with Entamoeba gingivalis among copper T 380A intrauterine device users in Egypt. Contraception 2012;85:108-12. https://doi.org/10.1016/j.contraception.2011.04.006

6. Levecke B, Dorny P, Vercammen F, Visser LG, van Esbroeck M, Vercruysse J, et al. Transmission of Entamoeba nuttalli and Trichuris trichiura from nonhuman primates to humans. Emerg Infect Dis. 2015;21:1871-2. https://doi.org/10.3201/eid2110.141456

7. Botero D, Restrepo M. Parasitosis humanas. $4^{\text {ta }}$ edición. Medellín: Ediciones Corporación para Investigaciones Biológicas; 2012. p. 725.

8. Najafia A, Mirzaeia A, Kermanjania A, Abdia J, Ghaderic A, Naserifara R. Molecular identification of Entamoeba histolytica from stool samples of Ilam, Iran. Comp Immunol Microbiol Infect Dis. 2019;63:145-7. https://doi.org/10.1016/j.cimid.2019.01.003

9. Rivero de Rodríguez Z. Detección de Entamoeba moshkovskii en humanos: un nuevo problema diagnóstico en la amebiasis. Kasmera. 2013;41:42-9.

10. Gilchrist CA. Entamoeba bangladeshi: An insight. Trop Parasitol. 2014;4:96-8. https://doi.org/10.4103/2229-5070.138536

11. Quintero R. Crecimiento y desarrollo psicológico al niño venezolano. Puericultura Atención Primaria en Salud infanto-juvenil. Maracaibo: Ediciones Psicopediátricas; 2001. p. 7-10.

12. Méndez H, De Méndez MC. Sociedad y Estratificación: Método Graffar-Méndez Castellano. Caracas: Editor Fundacredesa; 1994. p. 206.

13. Melvin D, Brooke M. Métodos de laboratorios para el diagnóstico de parasitosis intestinales. México: Editorial Interamericano; 1971. p. 198.

14. Rivero Z, Bracho A, Calchi M, Díaz I, Acurero E, Maldonado A, et al. Detección y diferenciación de Entamoeba histolytica y Entamoeba dispar mediante reacción en cadena de la polimerasa en individuos de una comunidad del Estado Zulia, Venezuela. Cad Saúde Pública. 2009;25:151-9. https://doi.org/10.1590/S0102-311X2009000100016 
15. Khairnar K, Parija S. A novel nested multiplex polymerase Chain Reaction (PCR). Assay for differential detection of E. histolytica, E. dispar and moshkovskii DNA in stool samples. BMC Microbiol. 2007;7:47. https://doi.org/10.1186/1471-2180-7-47

16. Ngui R, Angal L, Fakhrurrazi S, Ai Lian Y, Ling L, Ibrahim J, et al. Differentiating Entamoeba histolytica, Entamoeba dispar and Entamoeba moshkovskii using nested polymerase chain reaction (PCR) in rural communities in Malaysia. Parasit Vectors. 2012;5:187. https://doi.org/10.1186/1756-3305-5-187

17. Wayne D. Bioestadística. Base para el análisis de las ciencias de la salud. Cuarta edición. México, D.F.: Limusa Wiley; 2002. p. 665.

18. Bracho A, Rivero de Rodríguez Z, Arraiz N, Villalobos R, Urdaneta H. Detección de Entamoeba histolytica y Entamoeba dispar mediante PCR, en niños menores de cinco años con diarrea, en Maracaibo, Venezuela: estudio preliminar. Invest Clin. 2013;54:373-81.

19. Samie A, Mahlaule L, Mbati P, Nozaki T, ElBakri A. Prevalence and distribution of Entamoeba species in a rural community in northern South Africa. Food Waterborne Parasitol. 2020;18:e00076. https://doi.org/10.1016/j.fawpar.2020.e00076

20. Sharbatkhori M, Nazemalhosseini-Mojarad E, Cheraghali F, Maghsoodloorad FS, Taherkhani $\mathrm{H}$, Vakili MA. Discrimination of Entamoeba spp. in children with dysentery. Gastroenterol Hepatol Bed Bench. 2014;7:164-7.

21. López O, López M, Corredor V, Echeverri C, Pinilla A. Differentiation of Entamoeba histolytica from Entamoeba dispar using Gal/GalNAc-lectin and polymerase chain reaction. Rev Med Chile. 2012;140:476-83. https://doi.org/10.4067/S0034-98872012000400008

22. Calegar DA, Nunes BC, Monteiro KJ, Santos JP, Toma HK, Gomes TF, et al. Frequency and molecular characterisation of Entamoeba histolytica, Entamoeba dispar, Entamoeba moshkovskii, and Entamoeba hartmanni in the context of water scarcity in northeastern Brazil. Mem Inst Oswaldo Cruz. 2016;111:114-9. https://doi.org/10.1590/0074-02760150383

23. Abid T. Molecular identification of some species of Entamoeba isolated from patients with diarrhea in Afak city/Qadisiyah governorate using real-time PCR technique. Int J Recent Sci Res. 2016;7:11207-11.

24. Bahrami F, Haghighi A, Zamini G, Khademerfan M. Differential detection of Entamoeba histolytica, Entamoeba dispar and Entamoeba moshkovskii in faecal samples using nested multiplex PCR in west of Iran. Epidemiol Infect. 2019;147:E96. https://doi.org/10.1017/S0950268819000141

25. Saidin S, Abu Bakar A, Mohd Zain BM. Prevalence and associated risk factors of Entamoeba histolytica, E. dispar and E. moshkovskii infection among Orang Asli communities in Slim River, Perak. JSML. 2020;8:22-35.

26. Mora L, García A, De Donato M, Urdaneta H. Estudio epidemiológico y molecular de cepas de Entamoeba histolytica y Entamoeba dispar en pacientes con diarrea en Cumaná, estado Sucre, Venezuela. Invest Clin. 2008;49:225-37.

27. Roshdy MH, Abd El-Kader NM, Ali-Tammam M, Fuentes I, Mohamed MM, El-Sheikhand NA, et al. Molecular diagnosis of Entamoeba spp. versus microscopy in the Great Cairo. Acta Parasitol. 2017;62:188-91. https://doi.org/10.1515/ap-2017-0022

28. Haque R, Ali I, Clark C, Petri W. A case report of Entamoeba moshkovskii infection in a Bangladesh child. Parasitol Inter.1998;47:201-2.

29. Ali IKM, Hossain MB, Roy S, Ayeh-Kumi PF, Petri Jr W, Haque R, et al. Entamoeba moshkovskii infections in children, Bangladesh. Emerg Infect Dis. 2003;9:580-4. https://doi.org/10.3201/eid0905.020548

30. Levecke B, Dreesen L, Barrionuevo-Samaniego M, Ortiz WB, Praet N, Brandt J, et al. Molecular differentiation of Entamoeba spp. in a rural community of Loja province, South Ecuador. Trans R Soc Trop Med Hyg. 2011;105:737-9. https://doi.org/10.1016/j.trstmh.2011.08.010

31. Bachkanji AB. Identificación molecular de especies de Entamoeba en muestras fecales provenientes de pacientes del anexo pediátrico del "Hospital Luis Razetti" de Barcelona, Estado Anzoátegui y su relación con síntomas clínicos. (disertación). Anzoátegui: Universidad de Oriente; 2011.

32. López M, León C, Fonseca J, Reyes P, Moncada L, Olivera M, et al. Molecular epidemiology of Entamoeba: First description of Entamoeba moshkovskii in a rural area from central Colombia. PLoS ONE. 2015;14:1-11 https://doi.org/10.1371/journal.pone.0140302 
33. Soares NM, Azevedo HC, Pacheco FTF, De Souza JN, Del-Rei RP, Teixeira MCA, et al. A cross-sectional study of Entamoeba histolytica/dispar/moshkovskii complex in Salvador, Bahia, Brazil. Biomed Res Int. 2019;2019:7523670. https://doi.org/10.1155/2019/7523670

34. Ngui R, Hassan N, Soffyan N, Mohd-Shaharuddin N, Chang Li Y, Shuan C, et al. Copromolecular study of Entamoeba infection among the indigenous community in Malaysia: A first report on the species-specific prevalence of Entamoeba in dogs, Acta Tropica. 2020; 204:105334. https://doi.org/10.1016/j.actatropica.2020.105334

35. Castro AA, Bacalhau F, Silva FF, Avillez C, Batalheiro J. Entamoeba histolytica como causa de diarreia crônica. Rev Bras Med Fam Comunidade. 2019;14:1917. https://doi.org/10.5712/rbmfc14(41)1917

36. Aguilar-Solís BE, Sánchez-Rodríguez A, Sael-Lima M, Álvarez-Trejo VE. Amebiasis vulvar. Dermatol Rev Mex. 2017;61:142-6.

37. Blessmann J, Ali IK, Nu PA, Dinh BT, Viet TQ, Van AL, et al. Longitudinal study of intestinal Entamoeba histolytica infections in asymptomatic adult carriers. J Clin Microbiol. 2003;41:4745-50. https://doi.org/10.1128/jcm.41.10.4745-4750.2003

38. Andrade A, Santana T. Entamoeba histolytica como causa da amebíase. Rev Saúde Meio Ambiente. 2020;10:133-9

39. Aguilar-Rojas A, Castellanos-Castro S, Matondo M, Giai Q, Varet $\mathrm{H}$, Sismeiro O, et al. Insights into amebiasis using a human 3D-intestinal model. Cell Microbiol. 2020;22:e13203. https://doi.org/10.1111/cmi.13203

40. Hernández C, Moreno J, Olarte M, Meza E, Regalado J. Amebiasis intestinal: infección que prevalece. Ibn Sina. 2020;11:1-11.

41. Saavedra E, Olivos A. Amebiasis. Ciencia. 2017;68:14-7.

42. Ugboko HU, Nwinyi OC, Oranusi SU, Oyewal JO. Childhood diarrhoeal diseases in developing countries. Heliyon. 2020;6:e03690 https://doi.org/10.1016/j.heliyon.2020.e03690

43. Haque R, Mondai D, Kirkpatrick B, Akter S, Farr B, Sack B, et al. Epidemiologic and clinical characteristics of acute diarrhea with emphasis on Entamoeba histolytica infections in preschool children in an urban slum of Dhaka, Bangladesh. Am J Trop Med Hyg. 2003;69:398-405.

44. Akisu C, Aksoy U, Cetin H, Ustun S, Akisu M. Effect of human milk and colostrum on Entamoeba histolytica. World J Gastroenterol. 2004;10:741-2. https://doi.org/10.3748/wjg.v10.i5.741

45. Devera R, Aguilar K, Maurera R, Blanco Y, Amaya I, Velásquez V. Parasitosis intestinales en alumnos de la escuela básica nacional: "San José de Cacahual". San Félix, Estado Bolívar, Venezuela. Rev Academia. 2016;15:35-46.

46. Cociancica P, Torrusio S, Zonta ML, Navone G. Risk factors for intestinal parasitoses among children and youth of Buenos Aires, Argentina. One Health. 2020;9:100116 https://doi.org/10.1016/j.onehlt.2019.100116

47. Gholipoor Z, Khazan H, Azargashb E, Youssefi M, Rostami A. Prevalence and risk factors of intestinal parasite infections in Mazandaran province, North of Iran. Clin Epidemiol Global Health 2020;8:17-20. https://doi.org/10.1016/i.cegh.2019.03.010 